\title{
Study of Relationship between Emotional Intelligence and Organizational Commitment with Job Satisfaction of Staff of Ebne Sina Hospital by Using the NEO Personality Inventory
}

\author{
Marjan Mohammadian $^{1} *$, Farnoosh soltanmmohamadi ${ }^{2}$, Farshid ebrahimi $^{3}$
}

\section{ABSTRACT}

Purpose: The purpose of this study was identifying the relationship between emotional intelligence and organizational commitment with job satisfaction of staff of Ebne Sina Hospital. Method: For this purpose, NEO personality inventory and Minnesota job satisfaction questionnaires were used and after assuring of reliability and validity, Measuring tool were distributed among 125 sample of staffs of the Ebne Sina hospital. The research method is surveycorrelation. Results: The results showed that there is a significant positive relationship between emotional intelligence and organizational commitment with job satisfaction of staff of Ebne Sina hospital.

Keywords: Emotional intelligence, Organizational commitment, Job satisfaction, NEO personality inventory, Ebne Sina Hospital.

One of the main elements and fundamental in any organization is human resources of organization that definitely, regardless of size, internal motivations and desires of people in the organization, it will be difficult to achieve organizational goals. In this way, if organizations pay adequate attention to irritability, the role of various factors in motivating individuals, understanding the various dimensions and angles of staff and explore the capabilities and potential talents of staffs in the arena of the organization, they will be successful. Whatever compatibility and proportionality between personality and jobs is more, it will cause more job satisfaction and whatever compatibility and proportionality was less, it will cause less job satisfaction.

\footnotetext{
${ }^{1}$ M.A IN Clinical Psychologist, Islamic Azad University kohkiloye Branch, Kohkiloye, Iran

${ }^{2}$ Student of Clinical Psychology, Islamic Azad University (IAU), Garmsar Branch, Garmsar, Iran

${ }^{3} \mathrm{PhD}$ Student of Psychology, Kermanshah University, Kermanshah, Iran

*Responding Author

(C) 2016 I M Mohammadian, F Mmohamadi, F Ebrahimi; licensee IJIP. This is an Open Access Research distributed under the terms of the Creative Commons Attribution License (http://creativecommons.org/licenses/by/2.0), which permits unrestricted use, distribution, and reproduction in any Medium, provided the original work is properly cited.
} 


\section{Study of Relationship between Emotional Intelligence and Organizational Commitment with Job Satisfaction of Staff of Ebne Sina Hospital by Using the NEO Personality Inventory}

Job satisfaction as a general feeling of people towards their jobs has a direct impact on the individual, social and organizational life and it plays crucial role in mental and physical health, in contrast, Job dissatisfaction leads to reduction work mentality, performance and endangering the physical and mental health of staffs. The important point in studies of job satisfaction that has ambiguities, contradictions and complexities is determining the role of personality factors in job satisfaction, so that some researchers considered minimal impact on these factors and other researchers emphasize on the role of personality factors on organizational variables such as performance, organizational behavior, leadership and especially job satisfaction and believe that personality factors in dissatisfaction, deformation and leaving job is effective more than low income and talent (Davis and Newstrom, 1995). This relationship is expressed in the theory of Holland in the best aspect. Holland believes that in condition of proportion of job and personality, job satisfaction will reach the highest and Leaving job will reach minimized (Shafiabadi, 2007).

About the importance and necessity of the research should be said that undoubtedly human resources in the health organizations is theirs basic and fundamental assets and any health organization does not reach their goals Unless they use active and united personnel along with the organization's goals. Therefore, recognition of mental and spiritual various aspects of health sector personnel and provide their needs and reduce daily pressures and concerns can help to increase the efficiency and productivity of health and treatment staffs.

Generally job satisfaction study could have three major outcomes:

1. Results of the organization, including increasing of productivity, reducing of transfers and relocation of staff, reducing of absenteeism and increasing of the pleasant working relationship

2. Results of the individual, including more happiness, more self-realization and high mental health and motivation

3. Results of society, including better use of human resources, reducing of psychological problems and increasing of community building and development potential (Nouranipour, 2011)

Also Holland believes that people who have got more and better self-knowledge also will have got better choices and his theory is based on two important principles:

a) Choice of profession depends on type of personality.

b) Choice of profession has got direct relationship with one's attitude and orientation.

As mentioned, among the various features, a factor that can help significantly for people in appropriate profession choices is recognition of character. Maddi, knows character as stable set of tendencies and features that determine similarities and differences of psychological behavior (thoughts, feelings and actions) of people and may not be Understandable as a result of 


\section{Study of Relationship between Emotional Intelligence and Organizational Commitment with Job Satisfaction of Staff of Ebne Sina Hospital by Using the NEO Personality Inventory}

biological and social pressures of time (Maddi, 1989). Character attributes are the first status detection guide of cognitive and emotional of people and effect on the role of social-emotional and interpersonal or job behaviors of people (Moynihan \& Peterson, 2001). Psychologists offered various views about the dimensions of personality; including these views can be noted Bernereuter opinion that character has six aspects in it: Tend to nervousness, tend to be with her/himself, introversion-extraversion, bossy-submission, confidence and sociality (According to the Narimani and others, 2007). In psychology all human are identical in terms of having character; this means that everyone has got a character. But this character or self is not the same at all; but in anyone is certain that distinguishes him from others. The difference which people have with each other is so large that two of them cannot be found similar in a specific case. Every human and event is unique. However between humans and life events there are so much similarities that can be considered common points and this patterns of behavior is that they are interested in personality psychology. Personality Assessment is carried out to detect some mental disorders, classification of people for different kinds of work, implementation of scientific research and... . People have needs, expectations, incentives and specific goals based on their personality patterns. On the other hand, organizations also satisfy needs, specific expectations and based on their current goals, tasks and activities. So for each type of character, specific business environment and occupations is appropriate (Gharabaghi, 2003).

Investigation on human characteristics or personality traits as reliable and stable predictor could have a more decisive role in prediction of job satisfaction. Stability and predictability of personality which the new theories of psychology (character) emphasize on, expresses importance of the role of personality traits in different components and especially job satisfaction. According to studies, whatever compatibility and proportionality between personality and jobs is more, It will cause more job satisfaction, therefore, identifying traits and personality factors related to job satisfaction is very important and results of these research can be useful in the recruitment and selection of employees based on compatible personality patterns (Nouranipour, 2011).

Ebne Sina Hospital requests from applicants to complete NEO personality inventory test in the early stages of recruitment, in collaboration with psychologists.

NEO-FFI Personality Inventory has been proposed by Costa and McCrae (1989) and in Iran has been translated and used by Haghshenas (2004). NEO-FFI 60-items questionnaire was designed for concise and fast assess of 5 main characteristic factor ( neuroticism, extraversion, openness to experience, agreeableness, conscientiousness ) and each factor is composed from 12 items. In this study, after consultation with psychologist of center, extroversion dimension and conscientiousness dimension are considered respectively as emotional intelligence and 


\section{Study of Relationship between Emotional Intelligence and Organizational Commitment with Job Satisfaction of Staff of Ebne Sina Hospital by Using the NEO Personality Inventory}

organizational commitment. In the following pages, will be relied on emotional intelligence and organizational commitment completely.

\section{Emotional Intelligence}

Emotional Intelligence has its roots in the concept of 'social intelligence,' first identified by E.L. Thorndike in 1920. According to him social intelligence is the ability of understand and manage people in human relations. In early 1980, researchers conceptualized the idea of emotional intelligence systematically. The most famous of them was the concept of intra and interpersonal intelligence of Gardner (1983) and Steiner (1984) in the field of emotional literacy that was conceptualized of cornerstone that Salovey and Mayer was called it as emotional intelligence in the years 1990-1989. According to Salovey and Mayer, emotional intelligence is a form of social intelligence that involves the ability to monitor one's own and others' feelings and emotions, to discriminate among them, and use this information to guide one's thinking and action (Rezaiyan, 2008).

Based on previous studies, Bar-on and colleagues in 1997, described emotional intelligence as non-cognitive intelligence like this: a set of social and emotional skills which effect on the person's ability in dealing with the pressure and environmental applications.

In 1996, Daniel Goleman played a significant role in Publicize this concept with the publication of his famous book. In 1998, according to the findings of previous researchers, he described emotional intelligence like this: Emotional intelligence is a different kind of intelligence which included knowing of senses of self and use it to make appropriate decisions in life. In other words, emotional intelligence is expression of good ability to manage moods, mental condition and tension control and in fact, it is factor that makes people motivated and hope when they fail to achieve the goals (Ashforth\& Humphrey, 1995).

In general, Goleman's model of emotional intelligence competences are expressed in the four types of general ability:

1. Self-awareness - The ability of understanding of their emotions and strengths and weaknesses

2. Self-management - The ability of managing of their moods, tensions and internal capabilities

3. Social awareness - The ability of properly understanding of individuals and groups

4. Relationship management - The ability of handling of desired reactions in others

According to Goleman, an emotional competence is a learned capability based on emotional intelligence that results in outstanding performance at work. In other words, the amount of emotional intelligence determines the potential capability for learn of practical skills. According 


\section{Study of Relationship between Emotional Intelligence and Organizational Commitment with Job Satisfaction of Staff of Ebne Sina Hospital by Using the NEO Personality Inventory}

to Goleman, this model can explain individual differences in the performance of people at work (Goleman, 2001).

The above model is corrected from model which was released in 1998. As mentioned, in this research NEO personality inventory test and extroversion factor is used to identify emotional intelligence of staffs of Ebne Sina hospital.

\section{Organizational Commitment:}

Efficiency and development of every organization largely depends on correct application of human resource. As companies and organizations grow, problems of them also be added. Managers try to continually control their employees in relation to various issues. Managers believe that when a person to be hired in a organization, he must accepts all its conditions. Some managers insist on this issue that employee satisfaction can be increased through reward and encourage to do work. But truly, are not there other ways for better effectiveness in the organization given the fact that staffs live in financial pressure and more their attention and willingness to economic issues of work, apart from the rewards and possibilities such this?

\section{Organizational commitment is one of the important topics for researchers.}

In Oxford Dictionary (1996) Commitment is defined like this: Commitment is obligation that limits freedom of action. Organizational commitment has been defined in different ways like other organizational behavior. The most common way of dealing with organizational commitment is that organizational commitment is considered as emotional attachment to the organization. According this method, a person who is strongly committed, obtains his identity from organization, participates in the organization, and enjoys membership of organization (Saroughi, 1996).

Porter et al (1974) describes organizational commitment as "an attachment to the organization, characterised by an intention to remain in it; an identification with the values and goals of the organization; and a willingness to exert extra effort on its behalf”. O'Reilly and Chatman (1986) defined organizational commitment as "the psychological attachment felt by the person for the organization; it will reflect the degree to which the individual internalizes or adopts characteristics or perspectives of the organization" (Ranjbarian, 1996). Organizational commitment is the positive or negative attitude of people toward the entire organization not toward the their job. In organizational commitment, person has got strong feeling and loyalty to the organization and through that recognize his organization (Estron, 1998). Martyr Motahhari (1368) said about the commitment: Meaning of commitment is adherence to the principles and philosophy or contracts that humans believe and stable to. A Committed person who is loyal to his covenant and protects them for his goals. Sheldon (1971) described organizational commitment as an attitude or an orientation towards the organization, which links or attaches the identity of the person to the organization. Kanter defines organizational commitment as "the

(C) The International Journal of Indian Psychology, ISSN 2348-5396 (e)| ISSN: 2349-3429 (p) | 95 


\section{Study of Relationship between Emotional Intelligence and Organizational Commitment with Job Satisfaction of Staff of Ebne Sina Hospital by Using the NEO Personality Inventory}

willingness of social actors to give their energy and loyalty to social systems. Salancik (1977) said commitment is that "a state of being in which an individual become bound by his action and through these action to beliefs that sustain the activities of his own involvement".

According to the definitions of organizational commitment, according to researchers organizational commitment is often defined as follows:

Strong desire for survival of membership in a particular organization, desire for the immense efforts for the organization, strongly believe in the acceptance of values and goals of the organization. In other words, organizational commitment is an attitude about employee loyalty to the organization and is ongoing process that shows people attention to the organization, successfully and welfare of organizations through participation of people in corporate decisions.

In the present research organizational commitment is obtained from results of NEO personality inventory test. Conscientiousness factor is considered as the commitment in this test.

\section{Research History}

Organizations that have recognized the important role of human resources in improving efficiency, are aware about value of training of committed staff (Allahtavakkoli, Abedi and Salehnia, 2009). One of the contributing factors on developing human resources is emotional Intelligence. Emotional Intelligence includes our skills in knowing our and others feelings, sufficient skills in building healthy relationships with others, sense of responsibility and ability in maintain of our health (Pourkiani and Sabbagh Mollahoseini, 2008).

Emotional intelligence is correlated with factors that relate with organizational commitment. Goleman and his colleagues believe that emotional intelligence is used at all organizational levels, but at the managerial level, is very important (Eyvazi and Bagherzadeh, 2008). So that whatever emotional intelligence of managers and employees is more in the organization, as well as productivity of organization and employees will be added. Managers who have got emotional intelligence, are effective leaders and realize organization's goals with maximum efficiency, satisfaction and employee commitment and their approach in managing the organization is the type of grant self-control opportunities based on self-awareness (Mokhtaripour, Siadat and Amiri, 2006).

It is seemed that based on previous findings, leaders who have got emotional intelligence, are more committed to their organizations, act better at work environment, use emotions to improve decision-making and instill enthusiasm, confidence and cooperation in other works (Ansari Ranani and et al., 2008). So emotional intelligence can play an effective role in enhancing the ability of managers and employees that is related to organizational commitment. In this regard, also the results of Rezaeian and Koshtehgar (2008) showed there is a significant relationship 
Study of Relationship between Emotional Intelligence and Organizational Commitment with Job Satisfaction of Staff of Ebne Sina Hospital by Using the NEO Personality Inventory

between emotional intelligence and commitment, also among dimensions of emotional intelligence relationships management had the greatest impact on organizational commitment.

\section{RESEARCH SCHEME}

\section{Research purposes}

\section{Ideal purpose}

The ideal purpose of this study is that by identifying organizational commitment and emotional intelligence provides promotion of job Satisfaction of staffs of Ebne Sina hospital.

\section{General purpose}

General purpose of this study is investigation of relationship between emotional intelligence and organizational commitment with job satisfaction of staffs of Ebne Sina hospital.

\section{Special and practical purposes}

- Determination of amount of emotional intelligence (extraversion dimension) of staffs of Ebne Sina hospital with NEO personality inventory test

- Determination of amount of organizational commitment (conscientiousness dimension) of staffs of Ebne Sina hospital with NEO personality inventory test

- Determination of relationship between emotional intelligence and organizational commitment of staffs of Ebne Sina hospital

- Determination of relationship between emotional intelligence and organizational commitment with job satisfaction of staffs of Ebne Sina hospital

\section{Research Hypothesis}

1. There is relationship between emotional intelligence and organizational commitment of staffs of Ebne Sina hospital

2. There is relationship between emotional intelligence and organizational commitment with job satisfaction of staffs of Ebne Sina hospital

\section{Research Methodology}

In terms of purpose, this study is an applied research. Applied research is research that is used by human communities with use of result of fundamental research in order to improving and perfecting of behavior, methods, tools, equipment, products, structures and patterns. In terms of research method, this study is descriptive and correlational.

\section{Community and statistical sample}

The Statistical community of the research is staffs of the hospital that complete NEO personality inventory tests and research lasted a year. This study lasted September 21, 2012 to September 22, 2013. The sample consisted of 125 staffs of Ebne Sina hospitals. 


\section{Study of Relationship between Emotional Intelligence and Organizational Commitment with Job Satisfaction of Staff of Ebne Sina Hospital by Using the NEO Personality Inventory}

\section{Methods and tools of data collection}

Collecting data in this study was in two ways:

a) Field study including the implementation of both NEO questionnaire and Minnesota job satisfaction questionnaire

b) Library study including the use of documents, books, articles

\section{Statistical analysis method}

Given that research is descriptive and correlational, data that obtained from the questionnaires were analyzed after gathering information through documentation, editing, distributing and collecting questionnaires, using descriptive statistics (tables and graphs of frequency and percentage) and inferential statistics (Regression, multiple regression, t-test and analysis of variance) using SPSS software.

\section{Validity and reliability}

Usually there is two different general questions (but overlapping) in the evaluation of any measuring device. The first question is that how much sample is indicant and complete reference of responses that collected from questionnaires. The second question is that how much mentioned reference has got honesty in terms of conformity with favorite hidden features of its producer (Houman, 1991).

\section{Validity}

According to the standardized questionnaires, validity of questionnaires was assessed by an expert judgment (supervisors and consultants).

\section{Reliability}

Cronbach's alpha coefficient was used to obtain a reliability of questionnaire that 0.812 and 0.803 was obtained respectively for NEO inventory and Minnesota job satisfaction and it showed that tool used has good reliability.

\section{RESEARCH FINDINGS}

Testing the first hypothesis: There is relationship between emotional intelligence (extraversion dimension) and organizational commitment (conscientiousness dimension) of staffs of Ebne Sina hospital. For the evaluate of first hypothesis that shows a significant positive relationship between emotional intelligence and organizational commitment, correlation of subjects score were calculated in two mentioned variables using regression. The results show that there is a significant positive relationship between emotional intelligence and organizational commitment. $(\beta=0 / 41, \mathrm{t}(197)=6 / 4, \mathrm{p}<0 / 001)$

Testing the second hypothesis: There is relationship between emotional intelligence and organizational commitment with job satisfaction of staffs of Ebne Sina hospital. For the evaluate of second hypothesis that shows a significant positive relationship between emotional 


\section{Study of Relationship between Emotional Intelligence and Organizational Commitment with Job Satisfaction of Staff of Ebne Sina Hospital by Using the NEO Personality Inventory}

intelligence and organizational commitment with job satisfaction, correlation of subjects score were calculated in three mentioned variables using regression. The findings confirmed the hypothesis. $(\beta=0 / 34, t(197)=5 / 05, p<0 / 001)$

Other findings of this research can be noted as follows:

- $\quad$ Age of staffs has impact on organizational commitment. Because calculated $\mathrm{F}$ is larger than value of critical $\mathrm{F}$ of Alpha 0.01. Therefore it can be concluded with $99 \%$ confidence that people age has an impact on organizational commitment. So organizational commitment increase with increase of age.

- $\quad$ Education level of staffs has impact on organizational commitment. Because calculated $\mathrm{F}$ is larger than value of critical F of Alpha 0.01. Therefore it can be concluded with $99 \%$ confidence that education level of staffs has an impact on organizational commitment. So organizational commitment increase with increase of education level.

- $\quad$ Age of staffs has impact on emotional intelligence. Because calculated $\mathrm{F}$ is larger than value of critical F of Alpha 0.01 . Therefore it can be concluded with $99 \%$ confidence that people age has an impact on emotional intelligence. So emotional intelligence decrease with increase of age of staffs.

- $\quad$ Education level of staffs has impact on emotional intelligence. Because calculated $\mathrm{F}$ is larger than value of critical $\mathrm{F}$ of Alpha 0.01 . Therefore it can be concluded with $99 \%$ confidence that education level of staffs has an impact on emotional intelligence. So emotional intelligence increase with increase of education level.

\section{CONCLUSION}

The results showed that there is a significant relationship between emotional intelligence and organizational commitment and job satisfaction of staffs of Ebne Sina hospital. As mentioned earlier, emotional intelligence affects the performance of the organization. Hence, paying attention to recruitment of staffs with high emotional intelligence and organizational commitment can help organization in achievement of the short and long term strategic goals and can execute sense of cooperation and collaboration, which is one of the main components of survival of health organizations, in the organization, increase job satisfaction of staffs with establishment of emotional cohesion between staffs.

So, the author suggests that investigation of the personality characteristics of staffs and assessment of Semiannual of job satisfaction should be placed on the agenda of human resources departments and medical organizations at the time of recruitment for the considerable growth of the healthcare industry. 


\section{Study of Relationship between Emotional Intelligence and Organizational Commitment with Job Satisfaction of Staff of Ebne Sina Hospital by Using the NEO Personality Inventory}

\section{REFERENCES}

Allahtavakkoli, Z, Abedi, M, Salehnia, M, 2009, Investigation of effect of education of organizational citizenship behavior on increasing organizational commitment, Management vision, 9(33), 105-125

Ansari Ranani, Gh, Arsou, I, 2008, Emotional intelligence and transformational managers in the Iranian insurance companies, Insurance industry, 23 (1,2), 91-123

Ashforth, B.E, and Humphrey, R.H, 1995, Emotion in the workplace: a reappraisal, Human relations, Vol.48, No.2, pp.97-125

Davis, S, Newstrom, J, 1999, Organizational behavior at work, Tousi, M, Secon edition, Tehran, Center of governmental management training

Estron, H, 1998, Organizational commitment, Management in Education, Volume 5, No. 17

Eyvazi, Z, Bagherzadeh, D, 2008, Emotional Intelligence: A tool for managers, Journal of Human Development of Police, 5(17), 90-103

Gharabaghi, H, 2003, Investigation of relationship between personality characteristics and job satisfaction of staffs of Iran Tractor Factory, Master's Thesis, Faculty of Education and Psychology, University of Tabriz, 2-3

Goleman, D., 2001, An El-Based theory of performance, In cherniss, C., and Goleman, D., (Eds), The emotionally intelligent workplace: How to select for , Measure and improve emotional intelligence in individuals, groups and organizations, San Francisco, CA:Jossey-Bass, pp.27-44

Madi, S, 1989, Personality theories, Wadsworth, INC

Maynihan, L, Peterson, R, 2001, A contingent configuration approach to understanding the role of personality in organizational groups, Research in organizational, 23, 2001, 327-338

Mokhtaripour, M, Siadat, A, Amiri, Sh, 2006, Investigation of relationship between theory of emotional intelligence and the theories of leadership, Journal of executive management, 6(21), 39-57

Narimani, M, Khanbabazadeh, M, Farzaneh, S, 2007, Investigation of relationship between personality characteristics and job satisfaction of staffs of Ardabil University, Research Journal of Ardabil Medical University, The first issue, 83-77

Nouranipour, R, Akbarzadeh, A, 2011, Investigation of relationship between personality characteristics and job satisfaction of staffs of Tabriz Petrochemical Company in 2010, Journal of Educational Sciences, forth year, Issue 14

Porter, L.W, Motivation and work behavior, Mcgraw-Hill, Inc, 5th ed, 1991

Pourkiani, M, Sabbagh Mollahoseini, I, 2008, Investigation of relationship between emotional intelligence with effectiveness and innovations of staffs of organizations, Taken from the www.civilica.com

Ranjbarian, B, 1996, Organizational commitment, Faculty of Administrative Sciences and Economy, University of Isfahan, Tenth year, Issues 1 and 2

(c) The International Journal of Indian Psychology, ISSN 2348-5396 (e)| ISSN: 2349-3429 (p) | 100 


\section{Study of Relationship between Emotional Intelligence and Organizational Commitment with Job Satisfaction of Staff of Ebne Sina Hospital by Using the NEO Personality Inventory}

Rezaeian, A, Koshtehgar, A, 2008, Investigation of relationship between emotional intelligence and organizational commitment, Management vision, 7 (27), 27-39

Saroughi, A, 1996, Organizational commitment and its relationship with willing to leave of work, Issue 35 Shafiabadi, A, 2007, Theories of guidance and career advice, Tehran, Roshd

How to cite this article: M Mohammadian, F Mmohamadi, F Ebrahimi (2016), Study of Relationship between Emotional Intelligence and Organizational Commitment with Job Satisfaction of Staff of Ebne Sina Hospital by Using the NEO Personality Inventory, International Journal of Indian Psychology, Volume 3, Issue 3, No. 11, DIP: 18.01.199/20160303, ISBN: 978-1-365-21307-6

(C) The International Journal of Indian Psychology, ISSN 2348-5396 (e)| ISSN: 2349-3429 (p) | 101 